\title{
Technical note: Evaluation of an ear-attached real-time location monitoring system
}

\author{
B. Wolfger, ${ }^{*}$ B. W. Jones, $†$ K. Orsel, ${ }^{*}$ and J. M. Bewley ${ }^{1}$ \\ *Department of Production Animal Health, University of Calgary, Calgary, Alberta, Canada, T2N 4N1 \\ †Department of Animal and Food Sciences, University of Kentucky, Lexington 40546
}

\begin{abstract}
Position tracking of cows within the barn environment allows for determining behavioral patterns and activities. Such data might be used for detection of estrus and disease. A newly marketed real-time location monitoring system (Smartbow, Smartbow GmbH, Weibern, Austria) was tested in this study. Cow location was continuously monitored with the Smartbow tags mounted on the cow's ear, which sends low-frequency signals to receivers further transmitting the information to a server. Through incoming data, the server triangulates the location of the cow within the barn environment in real time. The validation of the system was carried out in 4 steps. The first 2 steps served as static testing steps (tags and 1 cow positioned at 30 reference points), and steps 3 and 4 were dynamic steps with cows moving in the barn environment. For $48 \mathrm{~h}$, locations of 15 cows were confirmed each hour by laser measurements performed by a team (step 3) or 1 observer (step 4). Interobserver variability was 0.83 $\mathrm{m}$ (range: 0.05 to $2.87 \mathrm{~m}$ ), and intraobserver variability had a range of 0.02 to $0.31 \mathrm{~m}$. In the 4 validation steps, the mean distance between observer laser measurements and Smartbow was between 1.22 and 1.80 $\mathrm{m}$. Step 4, with 334 observations, resulted in a mean distance difference of $1.22 \mathrm{~m}$ (standard error $=1.32 \mathrm{~m}$ ). Data can be used for development of algorithms to detect sick cows with changed behavioral patterns. Data may also be used to monitor cow responses to physical environment, potentially improving facility design. Time budgets in proximity to important barn features (i.e., feed bunk and water trough) and distances traveled can be calculated and used to identify cows in need of caretaker's attention and identify the cow's exact location in the barn.
\end{abstract}

Key words: position tracking, dairy facility, real-time location system

Received May 29, 2016.

Accepted October 25, 2016.

${ }^{1}$ Corresponding author: jbewley@uky.edu

\section{Technical Note}

The dairy industry has evolved to larger and more automated facilities. However, with an increase in number of cows, the number of caretakers has stayed the same (Barkema et al., 2015). To compensate for the lower caretaker-to-cow ratio, remote sensing technologies have been developed, which automatically and continuously collect behavior records on individual cows. Behavioral records have facilitated development of algorithms to detect disease (Huzzey et al., 2007; Thomsen et al., 2012) or estrus in dairy cattle (SaintDizier and Chastant-Maillard, 2012).

Position tracking of cows within the barn environment can be an indicator of activities (i.e., eating, drinking, and lying). A newly marketed location-monitoring system (Smartbow, Smartbow GmbH, Weibern, Austria) enables individual animal behavior monitoring by tracking cow movements within the barn environment over time. Tags mounted to the ear send lowfrequency signals to receivers, which transmit the information to a server. Through incoming data, the server triangulates the location of the cow within the barn environment in real-time. Time budgets in proximity to important barn features (i.e., stall area, feed bunk, and water trough) and distances traveled can be calculated and used in algorithms to identify cows in need of a caretaker's attention. The real-time location additionally enables farm personnel to locate cows requiring attention. The importance of the accuracy of a location monitoring device depends on the application of the system. Whereas lower accuracy might be sufficient to locate cows, determining behavior and interactions between cows might require higher accuracy. The overall objective of our study was, therefore, to determine the accuracy of the location monitoring system.

The study was conducted between September and November 2014 at the University of Kentucky Coldstream dairy research facility. The University of Kentucky Institutional Animal Care and Use Committee approved all procedures (Protocol number 2014-1308). Cows were housed in 2 freestall barns with cubicles 
and solid concrete flooring (Figure 1). One barn included 54 cubicles with Dual Chamber Cow Waterbeds (Advanced Comfort Technology, Sun Prairie, WI) as the stall base, and the other barn included 54 cubicles with rubber-filled mattresses (Promat Inc.,Woodstock, Ontario, Canada) as the stall base. Gates and a raised feedbunk - $27.4 \mathrm{~m}$ long, $1.37 \mathrm{~m}$ wide, $0.30 \mathrm{~m}$ deep, and $0.79 \mathrm{~m}$ high - available to both groups of cows from opposite sides of the bunk, separated the 2 freestall barns. Cows remained in 1 barn throughout the study period and stocking density never exceeded $100 \%$. Lactating cows were milked at 0430 and $1530 \mathrm{~h}$ daily. Cows were fed twice daily with ad libitum TMR (45.0\% corn silage, $25 \%$ alfalfa silage, $24 \%$ concentrate mix, $3 \%$ cottonseed whole, and $3 \%$ alfalfa hay as fed).

Cow location was continuously monitored with the Smartbow system (Smartbow GmbH). Every cow was equipped with the Smartbow tag, which was placed in the proximal half of the left ear. The dimensions of the tag were $52 \times 36 \times 17 \mathrm{~mm}$ with a weight of $34.1 \mathrm{~g}$. The tag had a range of $300 \mathrm{~m}$ within the line of sight. A transmission frequency of $1 \mathrm{~Hz}$ was used to transmit data from the tag to receivers (wall points). Wall points were placed at a height of $2.7 \mathrm{~m}$, approximately $15 \mathrm{~m}$ apart from each other, for receiver coverage throughout the barn. Data were transmitted from the wall points to a server located in the office area, where the exact location of the cow was calculated using the distance to the closest 4 sensors. A map of the barn was used to establish the origin ( $\mathrm{x}$ and $\mathrm{y}=0$; Figure 1 ). The $\mathrm{x}$-axis was defined as perpendicular to the feed alley, whereas the y-axis was parallel to the feed alley. Data transmission only occurred when 4 sensors were within line-of-sight to the tag aiming for a data transmission every second. The server transmitted cow positions to a computer, where the results were collected and stored.

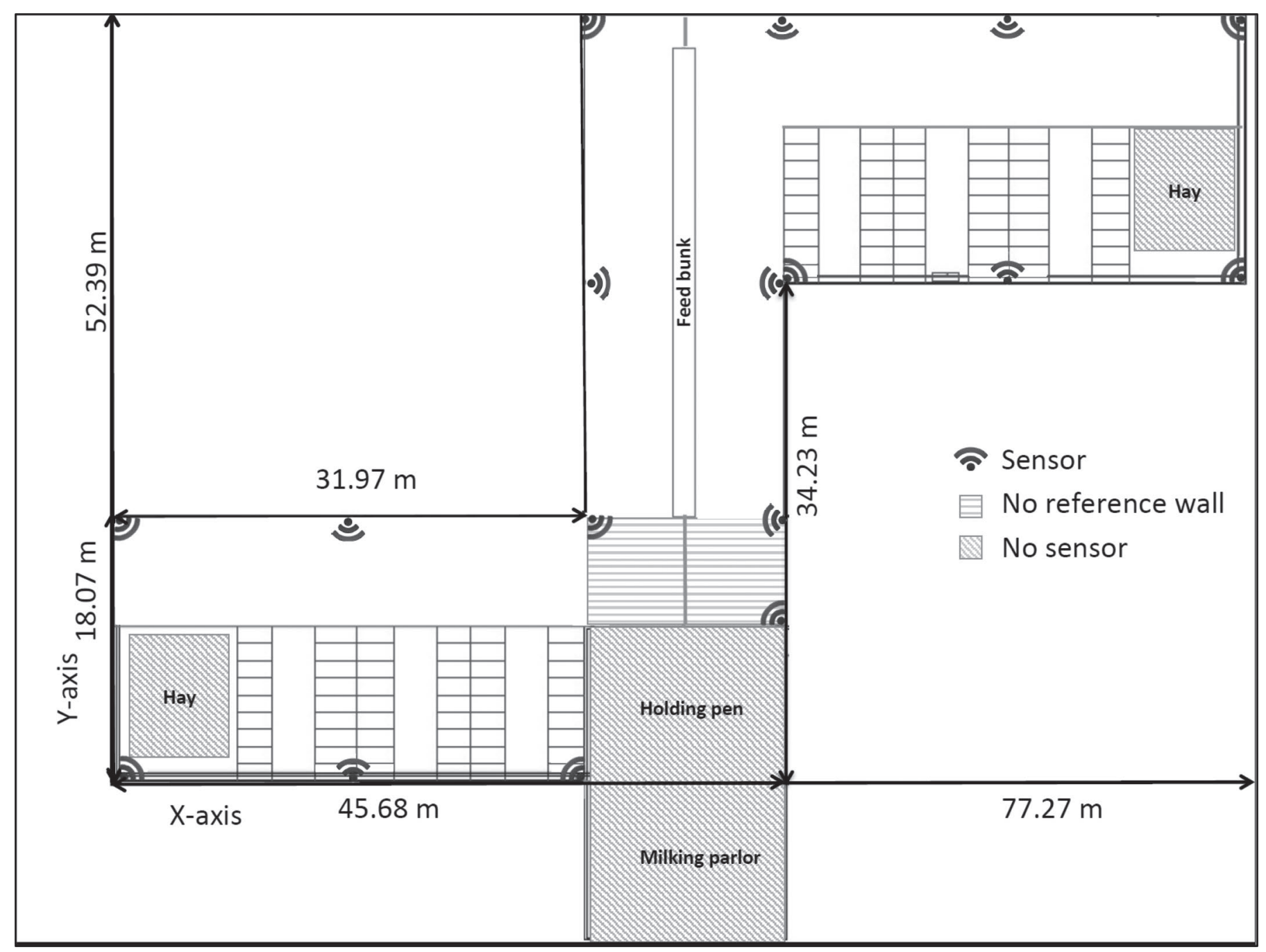

Figure 1. Plan showing the barn layout and the location of the wall-mounted receivers. 
The validation of the system was carried out in 4 steps, with the first 2 steps serving as static testing steps. The first step was conducted in the barn with no cows present, allowing for validation of the tag location with no disturbance. Thirty reference points equally distributed throughout the barn were identified using the map of the barn. The $\mathrm{x}$ and $\mathrm{y}$ coordinates of the reference points were measured with a laser distance measurer (accuracy $=1.5 \mathrm{~mm}$; range $=68.5 \mathrm{~m}$ ). The laser measurer was screwed onto a $152-\mathrm{cm}$ tall stake (Figure 2) that had 2 water levels to ensure that the measurements were made parallel to the floor. Two tags were strapped onto the stake at 152 and $76 \mathrm{~cm}$ to mimic a standing and lying cow. The stake was placed at all 30 reference points, and remained at each location for $3 \mathrm{~min}$; the exact time of the start (hh:mm:ss) of the positioning was recorded. This step validated the location of the tag without disturbance. The second step validated the tag location when mounted to the cow's eartag and included 1 haltered lactating Holstein dairy cow with an activated tag. The haltered cow was moved to the 30 reference points with known $\mathrm{x}$ and y coordinates; exact times when the cow arrived at and left the reference points were recorded. The cow remained at each point for at least 2 min with minimal movements before moving to the next point. During the third step (intensive validation), the location of each cow was validated with a laser measurement while freely moving in the herd. Positions of 15 lactating Holstein dairy cows equipped with the tag were tracked hourly for $48 \mathrm{~h}$. Fifteen trained observers measured the exact location of the cows. In 4-h shifts, one observer measured and one recorded the $\mathrm{x}$ and $\mathrm{y}$ axes of each cow hourly. Time and cow identification number was recorded before the observer approached the cow. The cow was observed for $10 \mathrm{~s}$ before noting the time and identification to ensure no movement. If the cow moved as the observer came closer, the closest estimate of the ear position was used to determine cow position, otherwise the stake was placed as close as possible to the ear of the cow. After checking the water levels, $\mathrm{x}$ and $\mathrm{y}$ coordinates were measured in a perpendicular line from the stake to the closest wall. The location of cows was not measured in the holding pen or during milking (2 $\times 2 \mathrm{~h}$ per day). Laser measurements could also not be performed when no reference walls for measurements were available to measure the $\mathrm{x}$ or $\mathrm{y}$ distance to the wall (gray stripped area in Figure 1). Interobserver variability was tested on 10 reference points with 4 observers (mean difference between observers $=0.83 \mathrm{~m}$; range $=0.05$ to $2.87 \mathrm{~m}$ ), and intraobserver variability was tested on 1 observer on repeated measurements of 5 reference points (range $=0.02$ to 0.31 ). During the final step, 1 experienced observer repeated step 3 on
20 cows for a total of $24 \mathrm{~h}$ (distributed throughout the day) over $3 \mathrm{~d}$ to remove the interobserver variability.

The statistical package Stata 11.2 (Stata Corp., College Station, TX) was used for data manipulation and statistics. To test accuracy of Smartbow, root mean square error (RMSE) was calculated for each time point. The coefficient of variation was calculated on the RMSE for each reference point during static testing, measuring the dispersion of Smartbow measurements when the ear tag was kept at the same spot (step 1 and 2). A moving average including the preceding 5 Smartbow records (5 s) was compared with the laser measurement in step 3 and 4 . The SAS package PROC MIXED (SAS 9.3, SAS Institute, Cary, NC) was used to describe the mean distance of Smartbow estimates from observations in step 3 and 4, with the cow as a random effect and repeated measures (autoregressive correlation structure). The RMSE was log-transformed to achieve normal distribution. Hour of the laser measurement was assessed as a fixed effect. Significance was defined when the $P$-value associated with the Wald-test was $<0.05$. The influence of outlier observations [third quartile $+3 \times$ interquartile range (IQR)] was tested in a sensitivity analysis by comparing coefficients between models with and without the outliers for steps 3 and 4 . For the first 3 steps, all data with $\mathrm{x}$-coordinates $<31.95 \mathrm{~m}$ were excluded from the analysis due to an error associated with the coordinates of 1 wall point; the error was corrected before step 4 started. Influence of location was tested using graphical representation (Figure 3).

Twenty-five and 13 observations were included in the analysis of step 1 and 2, respectively. The mean coefficients of variation were 41 (SD 17\%) and $43 \%$ (SD $26 \%$ ), median differences between laser and Smartbow measurements were $1.50(\mathrm{IQR}=0.85-2.24 \mathrm{~m})$ and 1.30 $\mathrm{m}(\mathrm{IQR}=1.06-3.02 \mathrm{~m})$ during step 1 and 2 , respectively.

In step 3, 386 observations were compared between Smartbow and laser. The mean difference was $1.80 \mathrm{~m}$ $(\mathrm{SE}=1.11 \mathrm{~m}$; Figure $4 \mathrm{a})$, and the variable hour was not significant in the model $(P=0.10)$. Nineteen observations were outliers with distances $>7.97 \mathrm{~m}$. When all outliers were excluded from the analysis, the mean distance was $1.55 \mathrm{~m}(\mathrm{SE}=1.09 \mathrm{~m})$. For step 4, 334 observations were compared between laser measurements taken by 1 observer and Smartbow. Twelve outliers were identified with distances $>5.63 \mathrm{~m}$. The mean distance, including the outliers, was $1.22 \mathrm{~m}(\mathrm{SE}=1.32$ $\mathrm{m}$; Figure $4 \mathrm{~b}$ ), and when the 12 outliers were excluded the mean distance was $1.09 \mathrm{~m}(\mathrm{SE}=1.08 \mathrm{~m})$.

In 4 validation steps, the mean distance between laser measurements and Smartbow was between 1.22 and $1.80 \mathrm{~m}$. The chosen reference standard for our study 

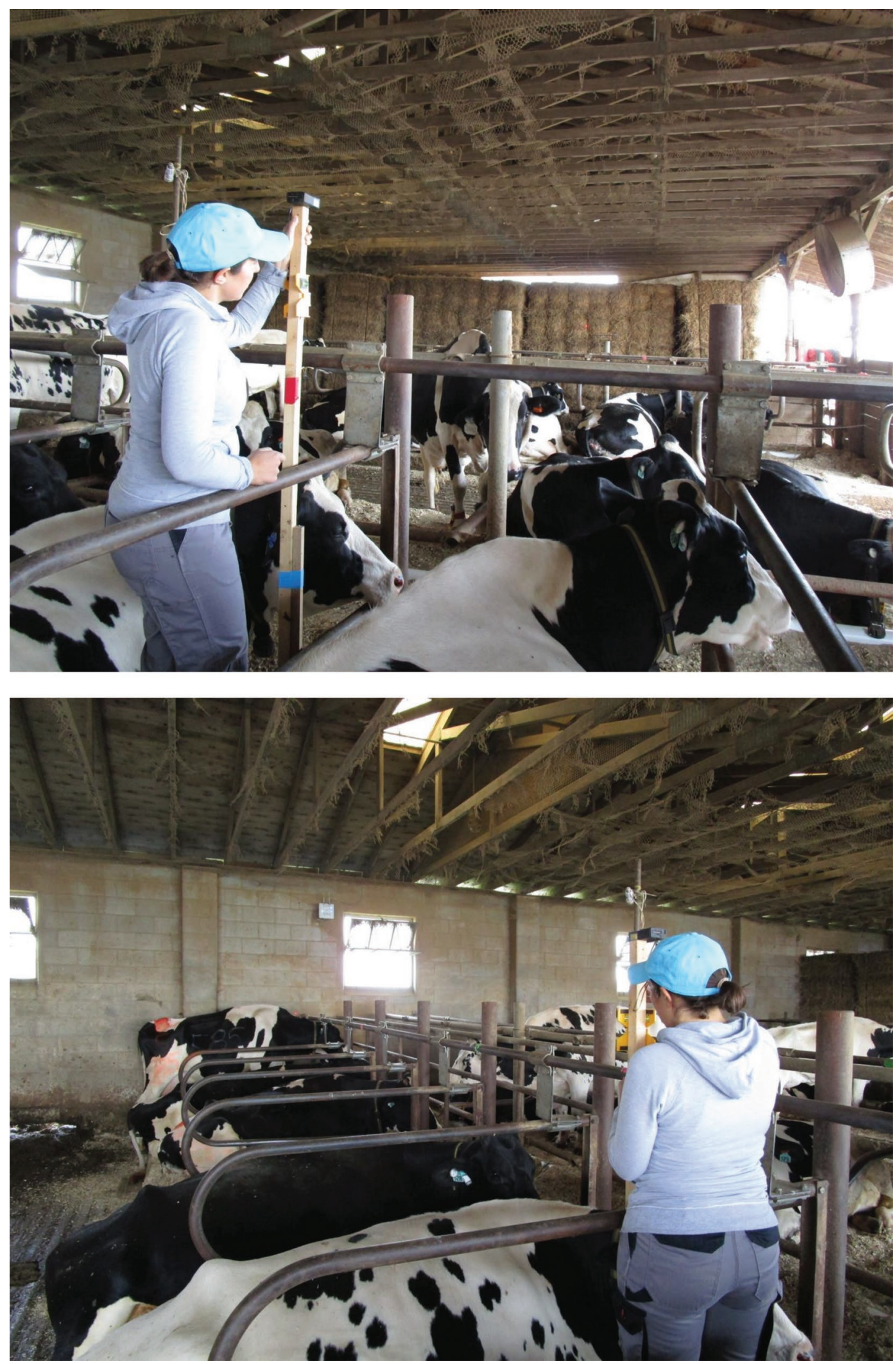

Figure 2. Stake used to attach the laser measuring device for more accurate measurements. Color version available online. 

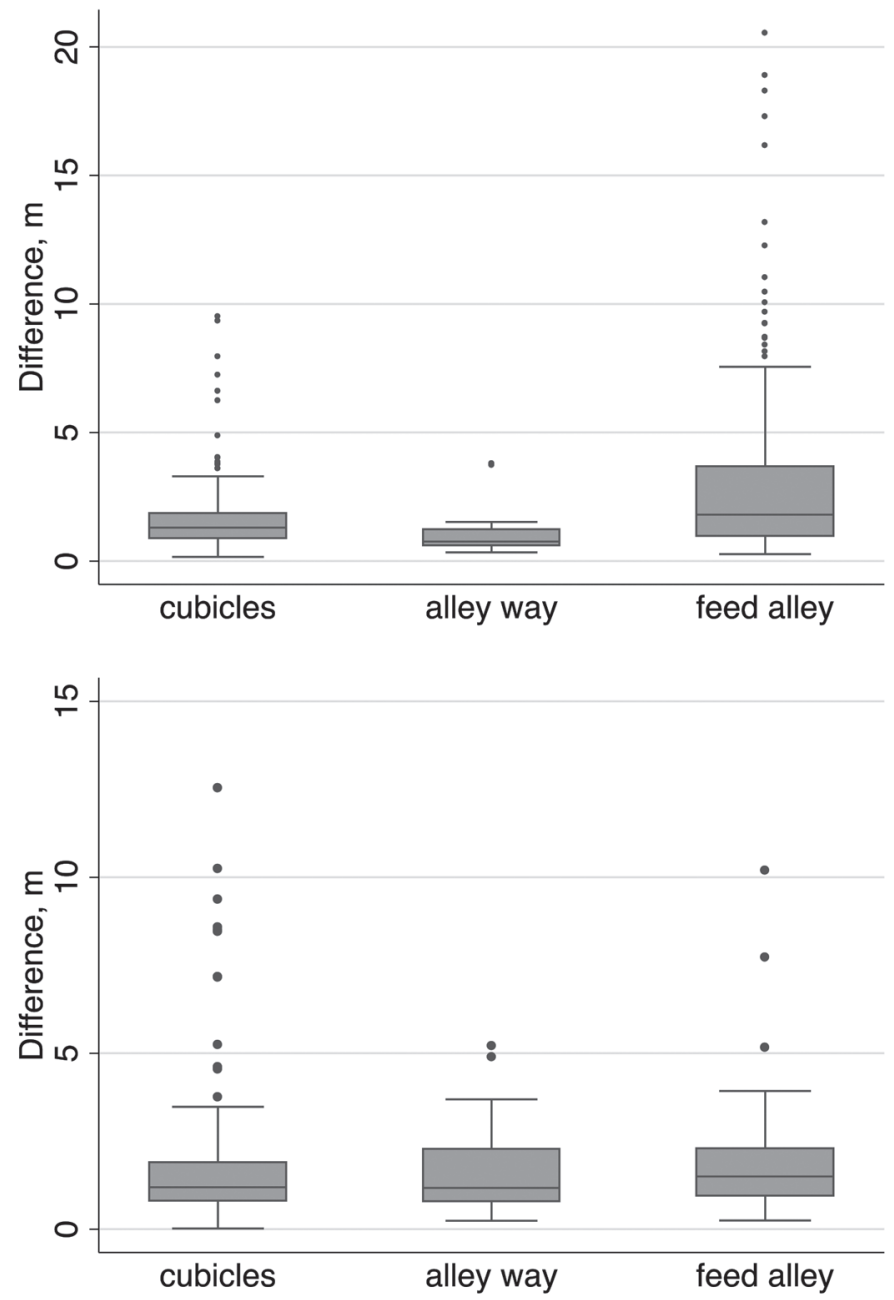

Figure 3. Distance between laser measurement and Smartbow (Smartbow GmbH, Weibern, Austria) position with multiple observers (top) and a single observer (bottom) by location within the barn. The box represents the 25 th and the 75 th percentile, the line the median, the whiskers the most extreme values, and the circles are outside the fence.

was laser measurement. As with any human-operated device, the probability of errors is not negligible. Despite intensive training of all observers, when measurements were performed by a single trained, experienced observer, the average difference was $0.6 \mathrm{~m}$ closer to Smartbow estimates compared with the overall distance when 7 observers measured the $\mathrm{x}$ and $\mathrm{y}$ axes.

Compared with global positioning systems, which are location monitoring devices that have previously been used in cow tracking, Smartbow can monitor location within the barn environment through ultra-low transmission frequency that does not interfere with metal structures of buildings. It records cattle position at a 1-s interval and, if matched with a map of the facility structures (such as feedbunks, water troughs, and

\section{a)}

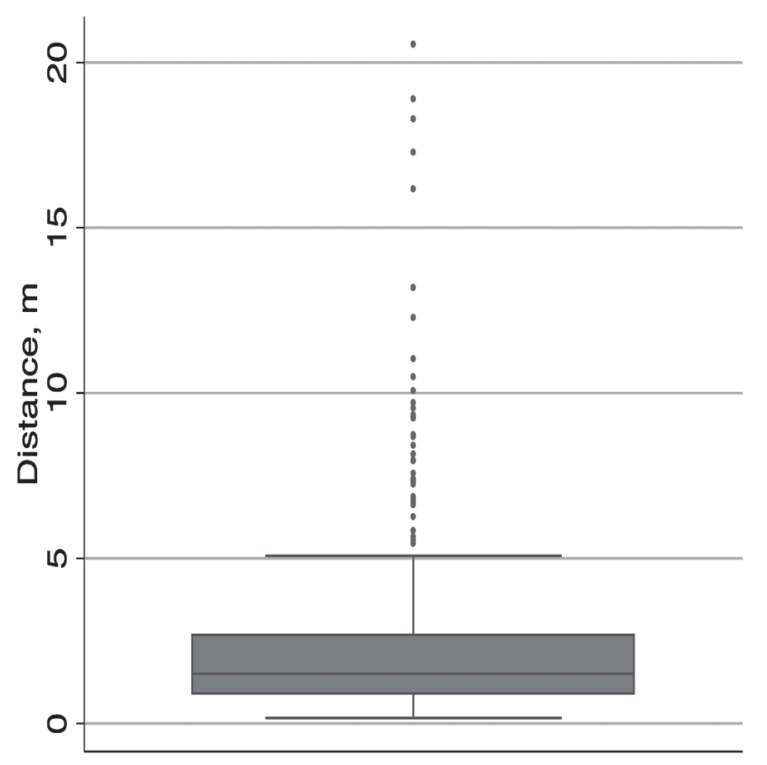

b)

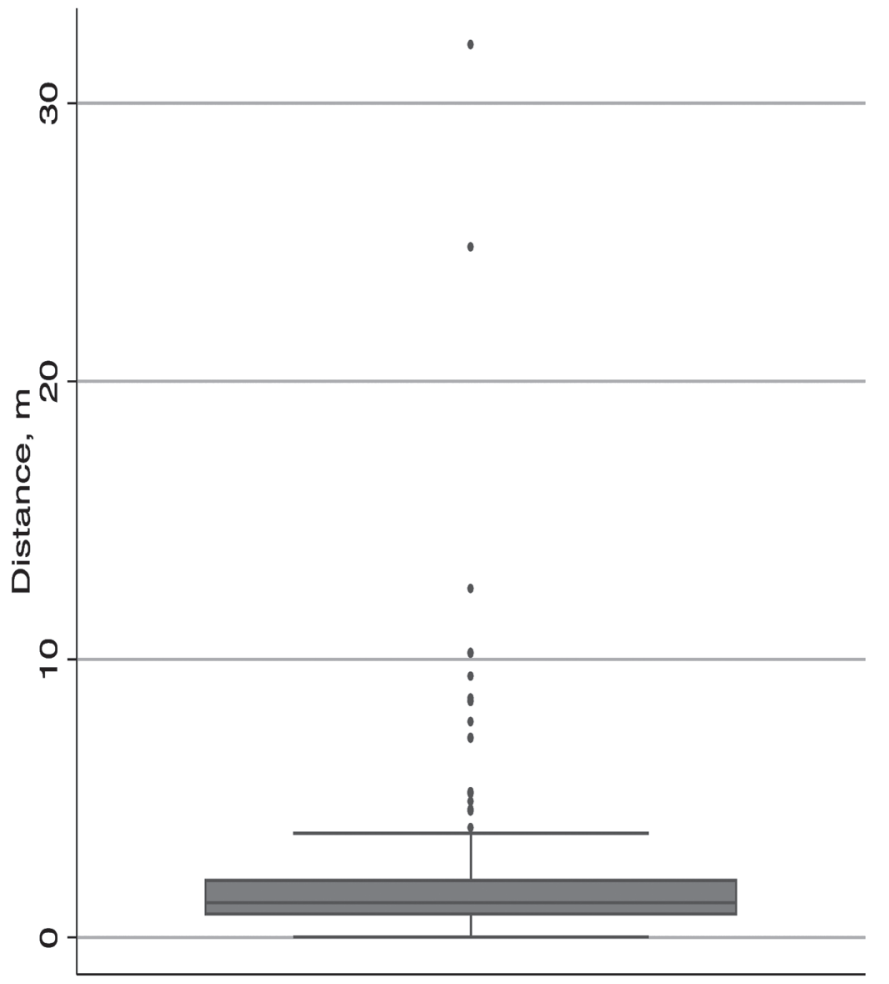

Figure 4. Distance between laser measurement and Smartbow (Smartbow GmbH, Weibern, Austria) position with multiple observers (a) and a single observer (b). The box represents the 25 th and the 75 th percentile, the line the median, the whiskers the most extreme values, and the circles are outside the fence. 
stalls), the percentages of time spent in proximity to certain structures and distance traveled can be calculated. To avoid data overload, the transmission interval can be matched to the needs (i.e., 5- or 10-s intervals for disease detection). Compared with Smartbow, which was within $2.93 \mathrm{~m} 95 \%$ of the time, accuracy of GPS collars can be as close as $8 \mathrm{~m} 95 \%$ of the time (Turner et al., 2000). Whereas $8 \mathrm{~m}$ might be sufficient to study resource use (Turner et al., 2000) and interactions between cattle and wildlife (Breck et al., 2012), higher resolution might be required to develop predictive algorithms for estrus and disease detection.

Although a different system (Ubisense, Denver, CO) that monitors real-time location has previously been used to assess time spent at the feed bunk and distance traveled (Theurer et al., 2013), to our knowledge the present study presents the first validation of a realtime monitoring system within the barn environment in cattle. The system shows great potential for research and commercial application, as well as development of algorithms to detect sick cows with changed behavioral patterns. Further investigation of the integrated alarm system to detect heat and disease will be necessary.

\section{ACKNOWLEDGMENTS}

The authors extend their sincerest thanks to Smartbow GmbH (Weibern, Austria) for support of this study. We thank all of the students for help in collecting data. Finally, we thank the Coldstream Dairy Farm staff for their dedication to the project.

\section{REFERENCES}

Barkema, H. W., M. A. von Keyserlingk, J. P. Kastelic, T. J. Lam, C. Luby, J. P. Roy, S. J. LeBlanc, G. P. Keefe, and D. F. Kelton. 2015. Invited review: Changes in the dairy industry affecting dairy cattle health and welfare. J. Dairy Sci. 98:7426-7445.

Breck, S., P. Clark, L. Howery, D. Johnson, B. Kluever, S. Smallidge, and A. Cibils. 2012. A perspective on livestock-wolf interactions on Western rangelands. Rangelands 34:6-11.

Huzzey, J. M., D. M. Veira, D. M. Weary, and M. A. von Keyserlingk. 2007. Prepartum behavior and dry matter intake identify dairy cows at risk for metritis. J. Dairy Sci. 90:3220-3233.

Saint-Dizier, M., and S. Chastant-Maillard. 2012. Towards an automated detection of oestrus in dairy cattle. Reprod. Dom. Anim. 47:1056-1061.

Theurer, M. E., D. E. Amrine, and B. J. White. 2013. Remote noninvasive assessment of pain and health status in cattle. Vet. Clin. North Am. Food Anim. Pract. 29:59-74.

Thomsen, P. T., L. Munksgaard, and J. T. Sørensen. 2012. Locomotion scores and lying behaviour are indicators of hoof lesions in dairy cows. Vet. J. 193:644-647.

Turner, L. W., M. C. Udal, B. T. Larson, and S. A. Sheare. 2000. Monitoring cattle behavior and pasture use with GPS and GIS. Can. J. Anim. Sci. 80:405-413. 